TITLE:

\title{
Triphenylboroxine and Triphenylborane as Anion Acceptors for Electrolyte in Fluoride Shuttle Batteries
}

\section{$\operatorname{AUTHOR}(S):$}

Konishi, Hiroaki; Minato, Taketoshi; Abe, Takeshi; Ogumi, Zempachi

\section{CITATION:}

Konishi, Hiroaki ... [et al]. Triphenylboroxine and Triphenylborane as Anion Acceptors for Electrolyte in Fluoride Shuttle Batteries. Chemistry Letters 2018, 47(11): 1346-1349

\section{ISSUE DATE:}

2018-11

URL:

http://hdl.handle.net/2433/243767

\section{RIGHT:}

(c) 2018 The Chemical Society of Japan.; Publisher permitted to deposit this accepted manuscript on this repository.; この論文は出版社版でありません。引用の際には出版社 版をご確認ご利用ください。; This is not the published version. Please cite only the published version. 


\title{
Triphenylboroxine and triphenylborane as anion acceptors for electrolyte in fluoride shuttle batteries
}

\author{
Hiroaki Konishi,*1, Taketoshi Minato,*2 Takeshi Abe, ${ }^{* 3}$ and Zempachi Ogumi, ${ }^{1}$ \\ ${ }^{1}$ Office of Society-Academia Collaboration for Innovation, Kyoto University, Gokasho, Uji, Kyoto 611-0011, Japan \\ ${ }^{2}$ Office of Society-Academia Collaboration for Innovation, Kyoto University, Katsura, Nishikyo, Kyoto 615-8510, Japan \\ ${ }^{3}$ Graduate School of Global Environmental Studies, Kyoto University, Katsura, Nishikyo, Kyoto 615-8510, Japan \\ E-mail: hiroaki.konishi.yj@hitachi.com (H. Konishi), minato.taketoshi.5x@kyoto-u.ac.jp (T. Minato), abe@elech.kuic.kyoto-u.ac.jp (T. \\ Abe)
}

For liquid-based fluoride shuttle batteries, electrolyte composed of organic solvent and supporting electrolyte salt is developed. To increase the solubility of supporting electrolyte salt in organic solvent, anion acceptors (triphenylboroxine or triphenylborane) are added. The addition of anion acceptor greatly increases the solubility of supporting electrolyte salt, and discharge-charge reaction of $\mathrm{BiF}_{3}$ electrode is confirmed in the prepared electrolytes.

Keywords: Fluoride shuttle battery, Anion acceptor, Bismuth fluoride

Currently, lithium ion batteries (LIBs) are widely used as power sources for electronic devices, and recent developments of devices have necessitated the improvement of energy density for batteries. ${ }^{1-3}$ Therefore, many research institutions develop high-energy-density electrode materials for LIBs ${ }^{4-6}$ and high-energy-density next-generation batteries. ${ }^{7-10}$ Recently, new all-solid-based and liquid-based batteries employing metal fluoride as an active material have been proposed. ${ }^{11-14} \mathrm{We}$ have focused on liquid-based fluoride shuttle batteries (FSBs). ${ }^{15}$ A schematic image of FSB is shown in Figure 1. For positive electrode, metal was formed $\left(\mathrm{MF}_{\mathrm{x}}+\mathrm{xe}^{-} \rightarrow \mathrm{M}+\mathrm{xF}^{-}\right)$during the discharge process, and metal fluoride is formed $\left(\mathrm{M}+\mathrm{xF}^{-} \rightarrow \mathrm{MF}_{\mathrm{x}}+\right.$ $\mathrm{xe}^{-}$) during the charge process. To facilitate the electrochemical reaction in a liquid-based electrolyte over a wide potential range, an electrolyte composed of an organic solvent and a supporting electrolyte salt such as a fluoride compound is used. However, fluoride compounds dissolved sparingly in the organic solvent. ${ }^{15}$ It is reported that boronbased compounds are used as anion acceptors (AAs), and the addition of AAs in the organic solvent was effective in dissolving insoluble lithium salt for LIBs. ${ }^{16-18} \mathrm{We}$ previously found fluorobis(2,4,6-trimethylphenyl)borane (FBTMPhB) significantly increased the solubility of cesium fluoride $(\mathrm{CsF})$ in bis[2-(2-methoxyethoxy)ethyl]ether (tetraglyme: G4) as an AA, and discharge and charge reactions of a $\mathrm{BiF}_{3}$ electrode were progressed using the $\mathrm{G} 4$ containing $\mathrm{CsF}$ and FBTMPhB as an electrolyte. ${ }^{15}$ In order to extend the usability of the FSB, the potential of other compounds as AA should be investigated for the electrolyte. In this work, two boron-containing compounds, triphenylboroxine (TPhBX) and triphenylborane (TPhB), were selected as potential AAs. The anion-accepting
45 tendency of boron-containing compounds has been reported 46 in the context of LIBs owing to the fact that the positively 47 charged boron ions in the AA attract negatively charged 48 fluoride ions, thus, increasing the solubility of fluoride 49 compounds in organic solvents. ${ }^{19-24}$ TPhBX contains a 50 boroxine ring and three phenyl groups, ${ }^{19,}{ }^{20}$ whereas $\mathrm{TPhB}$ 51 contains a boron atom bound to three phenyl groups. ${ }^{21-24}$ 52 Herein, the ability of $\mathrm{TPhBX}$ and $\mathrm{TPhB}$ to play the role of 53 AAs for electrolytes in FSBs and the electrochemical 54 performance of the $\mathrm{BiF}_{3}$ electrode were investigated using 55 prepared electrolytes.

56 The electrolytes for FSBs were prepared by dissolving $570.45 \mathrm{~mol} \mathrm{dm}^{-3} \mathrm{CsF}$ (Tokyo Chemical Industry Co., Ltd) and $580.5 \mathrm{~mol} \mathrm{dm}^{-3}$ TPhBX (Tokyo Chemical Industry Co., Ltd) 59 or $0.5 \mathrm{~mol} \mathrm{dm}^{-3} \mathrm{TPhB}$ (Tokyo Chemical Industry Co., Ltd) 60 in G4 (KISHIDA CHEMICAL Co., Ltd). These electrolytes 61 are denoted as CsF-TPhBX-G4 and CsF-TPhB-G4, 62 respectively, in the following text. Cyclic voltammetry (CV) 63 experiments were conducted to estimate the range of 64 working potential of these electrolytes. The three-electrode 65 electrochemical cell (EC FRONTIER CO., Ltd. VB7) setup 66 of the $\mathrm{CV}$ experiment comprised a platinum foil as the 67 working electrode, a platinum mesh as the counter electrode, 68 and a silver rod immersed in acetonitrile containing $0.1 \mathrm{~mol}$ $69 \mathrm{dm}^{-3}$ silver nitrate and $0.1 \mathrm{~mol} \mathrm{dm}{ }^{-3}$ tetraethylammonium 70 perchlorate as the reference electrode $(0.587 \mathrm{~V}$ vs. standard 71 hydrogen electrode). ${ }^{25} \mathrm{CV}$ experiments on the prepared 72 electrolytes were performed at room temperature using a 73 multipotentiostat (Biologic VMP-300) over a -4.0 to $2.0 \mathrm{~V}$ 74 (vs. ref.) potential range at a sweep rate of $0.1 \mathrm{mV} \mathrm{s}^{-1}$. $\mathrm{BiF}_{3}$ 75 (Fluorochem Ltd.) was used as the active material, and was 76 mixed with acetylene black and and polyvinylidene 77 difluoride $(60: 25: 15 \mathrm{wt} \%)$ to prepare the electrode. The 78 discharge and charge capacities of the prepared electrode 79 were measured by using it as the working electrode in the 80 three-electrode electrochemical cell with electrolytes CsF81 TPhBX-G4 and CsF-TPhB-G4, separately. The whole setup 82 containing the electrochemical cell was housed in an argon 83 atmosphere in a glovebox maintained at room temperature. 84 The charge-discharge measurements were performed using 85 a multipotentiostat (Biologic VMP-300) at $0.025 \mathrm{C}(1 \mathrm{C}=$ $86302 \mathrm{~mA} \mathrm{~g}^{-1}$ ). The electronic state of $\mathrm{Bi}$ from each working 87 electrode containing $\mathrm{BiF}_{3}$ was analyzed via X-ray 88 photoelectron spectroscopy (XPS; Ulvac Phi Quantera $89 \mathrm{SXM}^{\mathrm{TM}}$ ) using $\mathrm{Al} \mathrm{K} \alpha \mathrm{X}$-ray radiation in ultra-high vacuum 90 conditions. After discharging and charging the $\mathrm{BiF}_{3}$ 
Chemistry Letters, 47 (11), 1346-1349 (2018).

electrode, it was washed with G4, followed by 2 dimethylcarbonate to remove any residual electrolyte. Next, 3 the $\mathrm{BiF}_{3}$ electrodes were transferred into an XPS chamber 4 without air exposure using transfer vessels filled with high5 purity argon. In the XPS chamber, the surface of the $\mathrm{BiF}_{3}$ 6 electrode was etched to an estimated depth of $12 \mathrm{~nm}$ by an $7 \mathrm{Ar}^{+}$beam to remove any potential contaminants adsorbed 8 during the sample transfer. The binding energy of the 9 obtained spectra was calibrated to that of the $\mathrm{Bi} 4 \mathrm{f}_{7 / 2}$ peak of $10 \mathrm{Bi}$ metal at $156.9 \mathrm{eV}$. The intensity of the spectra was 11 normalized to the peak area of the $\mathrm{Bi}_{4 \mathrm{f}_{5 / 2}}$ peaks.

12

13

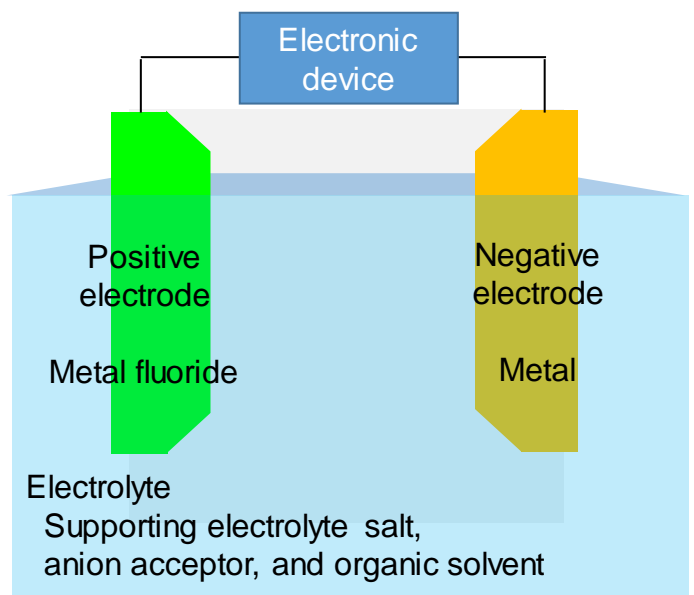

Positive electrode: $\mathrm{MF}_{\mathrm{x}}+\mathrm{xe}^{-} \rightleftarrows \mathrm{M}+\mathrm{xF}^{-}$

Negative electrode: (x/y) $\mathrm{M}^{\prime}+\mathrm{xF}^{-} \rightleftarrows \mathrm{xe}^{-}+(\mathrm{x} / \mathrm{y}) \mathrm{M}^{\prime} \mathrm{F}_{\mathrm{y}}$

14

16

Figure 1. A schematic image of FSB.

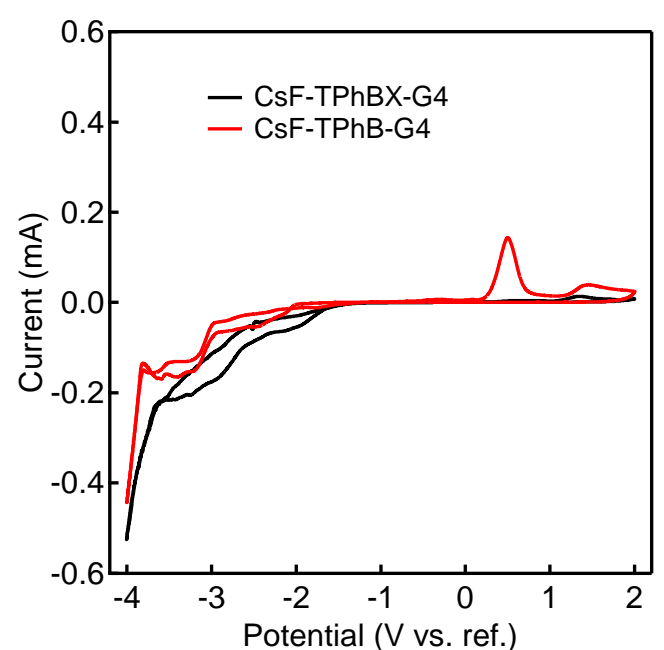

Figure 2. Cyclic voltammograms of a Pt electrode in CsF-TPhBX-G4 and CsF-TPhB-G4. Sweep rate: $0.1 \mathrm{~mA} \mathrm{~s}^{-1}$. Sweep range: $-4.0-2.0 \mathrm{~V}$ (vs. ref.).

The abilities of $\mathrm{TPhBX}$ and $\mathrm{TPhB}$ as $\mathrm{AAs}$ were investigated by observing the change in the solubility of $\mathrm{CsF}$ in G4. Previously, we reported that the solubility of CsF in the G4 is very low $\left(2.6 \times 10^{-5} \mathrm{~mol} \mathrm{dm}^{-3}\right)$ without any AAs in the solution. ${ }^{15}$ After adding $0.5 \mathrm{~mol} \mathrm{dm}^{-3} \mathrm{TPhBX}$ to $\mathrm{G} 4$, up to $0.45 \mathrm{~mol} \mathrm{dm}^{-3} \mathrm{CsF}$ dissolved in G4. This nearly fourorder-of-magnitude increase in the solubility of CsF in G4 suggests strong interaction of TPhBX with fluoride ions in G4. Similar results were obtained for $\mathrm{TPhB}$, suggesting the efficacy of both TPhBX and TPhB as AAs for G4.

The potential window of the prepared electrolytes was measured by $\mathrm{CV}$ (Figure 2). The reduction peaks in the $\mathrm{CV}$ appeared below -1.4 and $-1.6 \mathrm{~V}$ for CsF-TPhBX-G4 and CsF-TPhB-G4, respectively. With CsF-TPhBX-G4 as the electrolyte, weak oxidation peak was observed due to the decomposition of the electrolyte above $1.0 \mathrm{~V}$. With CsFTPhB-G4 as the electrolyte, oxidation peaks were observed above $0.2 \mathrm{~V}$. These results indicate that CsF-TPhBX-G4 and CsF-TPhB-G4 are stable between -1.4 and $1.0 \mathrm{~V}$, and between -1.6 and $0.2 \mathrm{~V}$, respectively.
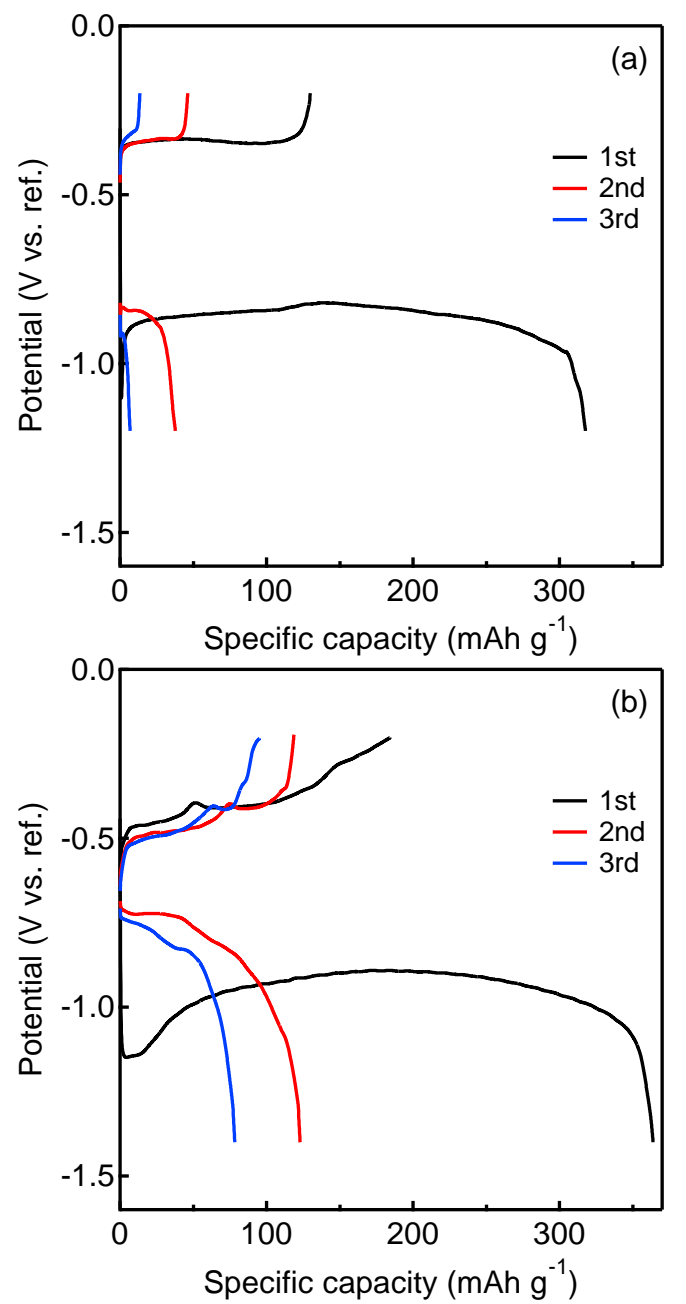

Figure 3. Discharge and charge curves of $\mathrm{BiF}_{3}$ electrode with electrolyte (a) CsF-TPhBX-G4 within potential range from -1.2 to -0.2 $\mathrm{V}$ (vs. ref.) and (b) CsF-TPhB-G4 within potential range from -1.4 to $0.2 \mathrm{~V}$ (vs. ref.) in the first, second, and third cycle.

Based on the improved solubility of $\mathrm{CsF}$ in $\mathrm{G} 4$ by addition of TPhBX or TPhB and electrochemical window measurements, the discharge and charge capacities of $\mathrm{BiF}_{3}$ were measured by using CsF-TPhBX-G4 and CsF-TPhB-G4 
1 as the electrolytes. The discharge cut-off potential was

2 limited to $0.2 \mathrm{~V}$ from the potential window (CsF-TPhBX-

3 G4: $-1.2 \mathrm{~V}$ and CsF-TPhB-G4: $-1.4 \mathrm{~V}$ ). The charge cut-off

4 potential was limited to $-0.2 \mathrm{~V}$. Without AAs, the discharge

5 capacity of the $\mathrm{BiF}_{3}$ electrode is very low $\left(2.0 \times 10^{-5} \mathrm{mAh}\right.$

$\left.6 \mathrm{~g}^{-1}\right) .{ }^{15}$ By using CsF-TPhBX-G4, clear improvements in the

7 electrochemical performance were observed, as evident

8 from the first discharge process in Figure 3(a). Here, a

9 plateau at around $-0.85 \mathrm{~V}$ was observed. The potential of

10 the plateau is almost the same as that for the plateau

11 observed in the electrolyte prepared by $\mathrm{CsF}$, FBTMPhB,

12 and G4 (CsF-FBTMPhB-G4). ${ }^{15}$ In CsF-FBTMPhB-G4, the

13 reduction of $\mathrm{BiF}_{3}$ to $\mathrm{Bi}$ metal was observed in the discharge

14 process. ${ }^{15}$ This suggests that the reduction of $\mathrm{BiF}_{3}$ can also

15 proceed in CsF-TPhBX-G4. A discharge capacity of 318

$16 \mathrm{mAh} \mathrm{g}^{-1}$ was observed in the first discharge process. The

17 observed capacity is higher than the theoretical capacity

$18\left(302 \mathrm{mAh} \mathrm{g}^{-1}\right)$ of the $\mathrm{BiF}_{3}$ electrode, suggesting the reaction

19 of the electrolyte with $\mathrm{Bi}$ metal, which forms during the

20 discharge process. Similar behavior was also observed in

21 CsF-FBTMPhB-G4. ${ }^{15}$ In the next charge process, a capacity

22 of $130 \mathrm{mAh} \mathrm{g}^{-1}$ was obtained. Although the charge capacity

23 was lower than the discharge capacity, the charge capacity

24 was clearly observed. By increasing the cycles, the observed

25 discharge/charge capacities of $\mathrm{BiF}_{3}$ in the CsF-TPhBX-G4

26 were changed to $318 / 130,38 / 46$, and $7 / 14 \mathrm{mAh} \mathrm{g}^{-1}$ in the

27 first, second, and third cycles, respectively. The discharge

28 and charge capacities decreased as the cycling progressed; however, the discharge and charge reactions progressed from the first to the third cycles. Figure 3(b) shows the discharge and charge curves of the $\mathrm{BiF}_{3}$ electrode in CsFTPhB-G4. The discharge/charge capacities of $\mathrm{BiF}_{3}$ in $\mathrm{CsF}-$ TPhB-G4 were 364/184, 123/119, and 78/95 $\mathrm{mAh} \mathrm{g}^{-1}$ in the first, second, and third cycles, respectively. The change of AA from TPhBX to TPhB improved the discharge and charge capacities and cycling performance. These results indicated that the discharge and charge reactions of the $\mathrm{BiF}_{3}$ electrode progressed in the electrolyte containing TPhBX or $\mathrm{TPhB}$, and the nature of AA affected the electrochemical performance of the $\mathrm{BiF}_{3}$ electrode for the FSB.

To confirm the progress of discharge $\left(\mathrm{BiF}_{3}+3 \mathrm{e}^{-} \rightarrow \mathrm{Bi}+\right.$ $\left.3 \mathrm{~F}^{-}\right)$and charge $\left(\mathrm{Bi}+3 \mathrm{~F}^{-} \rightarrow \mathrm{BiF}_{3}+3 \mathrm{e}^{-}\right)$reactions in the prepared electrolytes, the changes in the electronic state of $\mathrm{Bi}$ in the $\mathrm{BiF}_{3}$ electrode during the discharge and charge processes were investigated by XPS. The Bi $4 \mathrm{f}$ spectra of the $\mathrm{BiF}_{3}$ electrode in the pristine, fully discharged, and fully charged states prepared in the CsF-TPhBX-G4 and CsFTPhB-G4 are shown in Figure 4. In Figure 4(a), in the pristine state, large peaks were observed at 160.5 and 165.8 $\mathrm{eV}$, which are assigned to $\mathrm{Bi} 4 \mathrm{f}_{7 / 2}$ and $4 \mathrm{f}_{5 / 2}$ spectra for $\mathrm{Bi}^{3+}$ in $\mathrm{BiF}_{3} .{ }^{26,27}$ Furthermore, peaks of smaller intensity were observed at 156.9 and $162.2 \mathrm{eV}$, which are assigned to the Bi $4 f_{7 / 2}$ and $4 f_{5 / 2}$ spectra of Bi metal, respectively. ${ }^{26-28}$ This is due to the reduction of $\mathrm{BiF}_{3}$ by the $\mathrm{Ar}^{+}$sputtering.
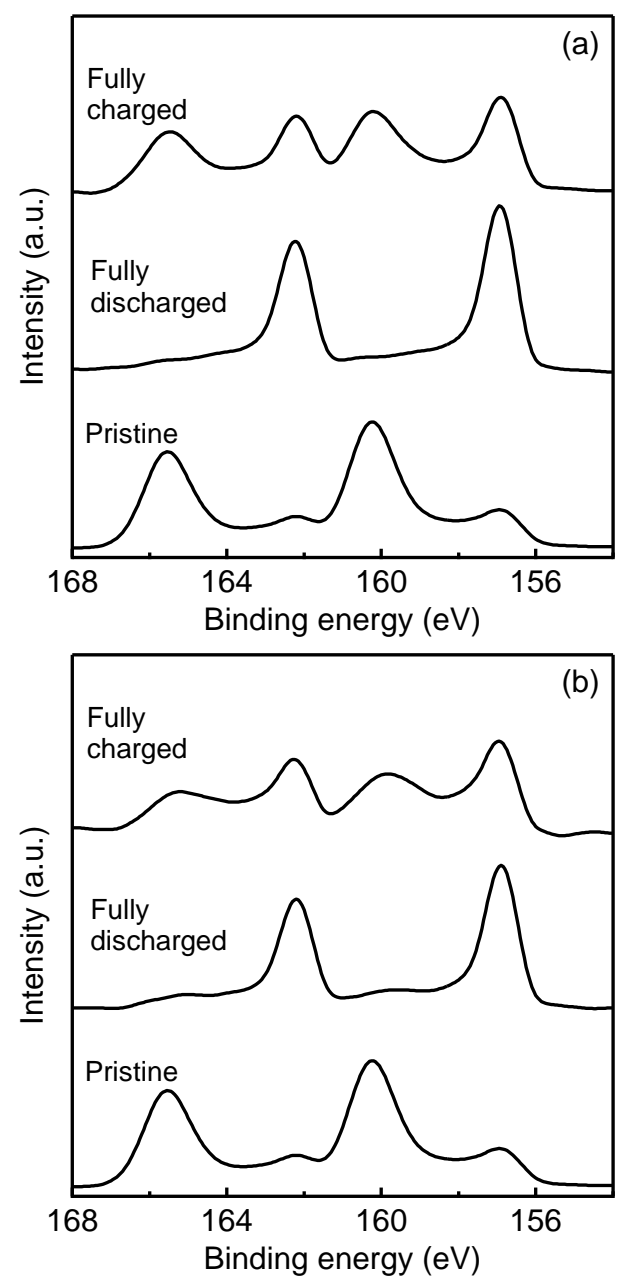

Figure 4. $\mathrm{Bi} 4 \mathrm{f}$ spectra of $\mathrm{BiF}_{3}$ electrode during the discharge and charge processes in the first cycle [Electrolyte: (a) CsF-TPhBX-G4 and (b) CsF-TPhB-G4].

From the pristine to fully discharged state, the peaks assigned to $\mathrm{Bi}$ metal enlarged and the peaks assigned to $\mathrm{Bi}^{3+}$ diminished, indicating that $\mathrm{Bi}$ is reduced during discharging. From the fully discharged to fully charged states, the peaks assigned to $\mathrm{Bi}^{3+}$ appeared and the peaks assigned to $\mathrm{Bi}$ metal became smaller. This indicates that $\mathrm{Bi}$ is oxidized during charging. As shown in Figure 4(b), the changes in the spectra from the pristine to fully discharged, followed by fully charged state are similar for CsF-TPhB-G4 and CsFTPhBX-G4 (Figure 4(a)). This indicates that $\mathrm{Bi}$ is reduced during discharging and oxidized during charging when using CsF-TPhB-G4. These results support the progress of discharge and charge reactions in both electrolytes.

In summary, the addition of TPhBX and TPhB greatly improved the solubility of $\mathrm{CsF}$ in $\mathrm{G} 4$. The discharge and charge reactions of the $\mathrm{BiF}_{3}$ electrode can be progressed using an electrolyte containing $\mathrm{TPhBX}$ or $\mathrm{TPhB}$. The cycling performance of the $\mathrm{BiF}_{3}$ electrode in the electrolyte with $\mathrm{TPhB}$ was better than that with $\mathrm{TPhBX}$. The boroncontaining compounds can play the role of AAs, and the G4 containing these compounds can be used as electrolytes in 
1 FSBs. The electrochemical performance of the $\mathrm{BiF}_{3}$

2 electrode was affected by the nature of AA in the electrolyte.

3 Future work will attempt to investigate the effect of AA

4 nature on the electrochemical performance of the $\mathrm{BiF}_{3}$

5 electrode and to improve the cycling performance of the

$6 \mathrm{BiF}_{3}$ electrode.

7

8 This work was supported by the Research and 9 Development Initiative for Scientific Innovation of New

10 Generation Batteries (RISING) and Research and 11 Development Initiative for Scientific Innovation of New 12 Generation Batteries 2 (RISING2) projects from the New 13 Energy and Industrial Technology Development 14 Organization (NEDO), Japan. The authors thank Ms. 15 Kiyomi Ishizawa, Ms. Ryoko Masuda, and Ms. Hisayo 16 Ikeda for their experimental support.

\section{References and Notes}

Y. Nishi, J. Power Sources 2001, 100, 101.

2 Y. Wang, B. Liu, Q. Li, S. Cartmell, S. Ferrara, Z.D. Deng, J. Xiao, J. Power Sources 2015, 286, 330.

3 T. Minato, T. Abe, Prog. Surf. Sci. 2017, 92, 240.

4 Z. Lu, D.D. MacNeil, J.R. Dahn, Electrochem. Solid State Lett. 2001, 4, A191.

5 J.O. Besenhard, J. Yang, M. Winter, J. Power Sources 1997, 68, 87.

6 M.N. Obrovac, L. Christensen, Electrochem. Solid State Lett. 2004, 7, A93.

7 C. Delmas, J.J. Braconnier, C. Fouassier, P. Hagenmuller, Solid State Ion. 1981, 3-4, 165.

8 D. Aurbach, Z. Lu, A. Schechter, Y. Gofer, H. Gizbar, R. Turgeman, Y. Cohen, M. Moshkovich, E. Levi, Nature 2000, 407,724 .

9 A. Eftekhari, J. Power Sources 2004, 126, 221.

10 K.M. Abraham, Z. Jiang, J. Electrochem. Soc. 1996, 143, 1.

11 M. A. Reddy, M. Fichtner, J. Mater. Chem. 2011, 21, 17059.

12 C. Rongeat, M. A. Reddy, R. Witter, M. Fichtner, J. Phys. Chem. C 2013, 117, 4943.

13 A. Grenier, A.Porras-Gutierrez, H. Groult, K.A. Beyer, O.J. Borkiewicz, K.W. Chapman, D. Dambournet, J. Mater. Chem. A 2017, 5,15700 .

14 M.A. Nowroozi, K. Wissel, J. Rohrer, A.R. Munnangi, O. Clemens, Chem. Mater. 2017, 29, 3441.

15 H. Konishi, T. Minato, T. Abe, Z. Ogumi, J. Electrochem. Soc. 2017, 164, A3702.

16 H.S. Lee, X. Sun, X.Q. yang, J. McBreen, J. Electrochem. Soc. 2002, 149, A1460.

17 B. Xie, H.S. Lee, H. Li, X.Q. Yang, J. McBreen, L.Q. Chen, Electrochem. Commun. 2008, 10, 1195.

18 L.F. Li, H.S. Lee, H. Li, X.Q. Yang, K.W. Nam, W.S. Yoon, J. McBreen, X.J. Huang, J. Power Sources 2008, 184, 517.

19 V.P. Reddy, M. Blanco, R. Bugga, J. Power Sources 2014, 247, 813.

20 V.P. Reddy, E. Sinn, N. Hosmane, J. Organometal. Chem. 2015, 798,5 .

21 M. Marcinek, G.Z. Zukowska, W. Wieczorek, Electrochim. Acta $\mathbf{2 0 0 5}, 50,3934$

22 G. Zukowska, M. Szczechura, M. Marcinek, A. Zubrowska, A. Adamczyk-Wozniak, A. Sporzynski, W. Wieczorek, ECS Transactions 2009, 16, 105.

23 M. Ciosek, M. Marcinek, G.Z. Zukowska, W. Wieczorek, Electrochim. Acta 2009, 54, 4487.

24 A. Adamczyk-Wozniak, M. Jakubczyk, A. Sporzynski, G. Zukowska, Inorg. Chem. Commun. 2011, 14, 1753.

25 V.V. Pavlishchuk, A.W. Addison, Inorg. Chim. Acta 2000, 298, 97. 66
Chemistry Letters, 47 (11), 1346-1349 (2018).

6726 W.E. Morgan, W.J. Stec, J.R.V. Wazer, Inorg. Chem. 1973, 12, 68953.

6927 A.J. Gmitter, A. Halajko, P.J. Sideris, S.G. Greenbaum, G.G. 70 Amatucci, Electrochim. Acta 2013, 88, 735.

7128 B. Hu, X. Wang, H. Shu, X. Yang, L. Liu, Y. Song, Q. Wei, H. $72 \mathrm{Hu}, \mathrm{H} . \mathrm{Wu}, \mathrm{L}$. Jiang, X. Liu, Electrochim. Acta 2013, 102, 8 
